\title{
The Ramsay Memorial in Westminster Abbey.
}

$\mathrm{T}$ is a somewhat inhuman trait among British men of science, and in particular among chemists, that they have not sufficiently secured public honour for their fathers who spiritually begat them. Boyle's resting-place is unknown, and there is no express memorial to him in the Royal Society, of which he was the greatest founder; and to the chief of his chemical successors, however well remembered in the records of their science, tangible monuments for the most part exist only where purely local pride has preserved or erected them. The ceremony of November 3 , therefore, when a medallion tablet in memory of Sir William Ramsay was unveiled in Westminster Abbey, was a most welcome manifestation of a world-wide tribute.

The British nation at large was represented in the person of H.R.H. the Duke of York (the Prince of Wales being prevented by a riding mishap); Sir Charles Sherrington, president of the Royal Society, stood for British science, together with a large gathering which included many of its foremost followers ; Prof. Le Chatelier came from Paris as president of the Academy of Sciences; while the presence of the ambassadors and ministers of no fewer than twentyone countries attested the far-reaching fame of Ramsay's achievements. Lady Ramsay was present, with Mr. W. G. Ramsay, and Dr. and Mrs. H. L. Tidy and their children. A short choral service was held in the nave, during which the Duke

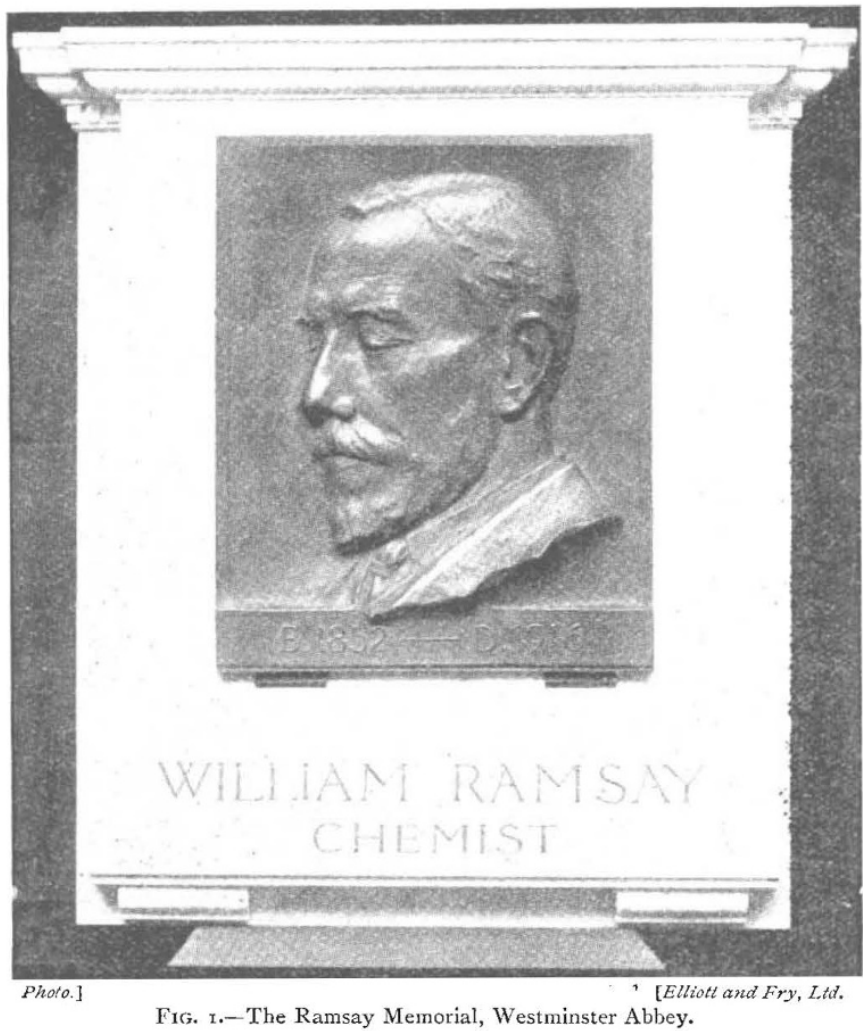

of chemical engineering at University College, London, where Ramsay taught and worked for 26 years; there, also, an annual Ramsay medal has been founded.

The Abbey bronze, which was executed by Mr. C. L. Hartwell, A.R.A., is illustrated in the accompanying photograph (Fig. I). The artist has been compelled, owing to the nature of the only position available in the Abbey, to give to the eyes a downcast expression which in life they rarely assumed. Probably no medium could convey the inward and outward sparkle which lit Ramsay's eyes under their characteristically lifted brows; and his open glance and the quick charm of his smile defy portrayal.

As a chemist, Ramsay had three great gifts in nearly equal degree : boldness of imagination, amazing audacity in conceiving experiments, and extraordinary constructional and manipulative deftness in carrying them out. Of his earlier researches the importance is exemplified by his discovery of the nature of Brownian movement, by the work embodied in the Ramsay-Young: equation, and by that which gave the RamsayEötvös method for measuring molecular association in liquids. In r894, he alone of chemists had the courage to see in Rayleigh's abnormal nitrogen-densities the indication of a new atmospheric element and to seek it and find it; his discovery of helium came as a dramatic reward for a search after further sources of of York unveiled the tablet and offered it to the Dean, who in dedicating it referred to the panels commemorative of Joule, Kelvin, Hooker, Darwin, and Lister, among which it is to be permanently set. The medallion was provided from the Ramsay Memorial Fund.

This fund, begun in I9I 7 , consists of nearly $58,000 l$. raised by private subscription all over the world; and the capitalised value of the additional endowments by Dominion and foreign governments is as much again. Eleven Ramsay Fellowships, each of annual value at least $300 l$., enable promising research-students to come to carry on work in any selected chemical laboratory in Britain, from Canada, France, Switzerland, Greece, Italy, Norway, Sweden, Denmark, Spain, Holland, and Japan ; and there are also British Ramsay Fellowships, including one specially connected with Glasgow, Ramsay's alma mater. From the remainder of the fund, $25,000 l$. is being devoted to a laboratory argon; and with the advent of liquid air he, with Travers, drove on with irresistible impetus to the detection and isolation of neon, krypton, and xenon. Only Berzelius has discovered as many new elements ; no one but Ramsay has laid bare a complete fresh scope; and the experimental proof that helium is generated during radioactive change founded the era of the transmutation of elements. Possibly the finest example of his skill was given when, with Whytlaw-Gray, he measured the density of onethousandth of a milligram of gaseous radium-emanation-the last member of his own group of inert gases.

Like Priestley and Davy, Ramsay opened up a new world for science; and physics, chemistry, and even astronomy are enriched, not alone by the discoveries which he made, but also by the methods which he devised and so freely handed on to others. I. M. and unforeseen group. In radioactivity he found 